\title{
AS IDÉIAS DA CEPAL SOBRE A QUESTÃo AGRÁRIA LATINO-AMERICANA
}

\author{
Anderson César G. T. Pellegrino*
}

\section{INTRODUÇÃO}

Há cinqüenta anos, Raúl PREBISCH e a Cepal lançavam o documento El desarrollo económico de la América Latina y algunos de sus principales problemas, posteriormente conhecido como "manifesto latino-americano" da Cepal. Em tal documento constavam as idéias-chave de uma linha de pensamento que surgia para alterar, de modo significativo, as reflexões acerca das problemáticas próprias do desenvolvimento econômico nas nações periféricas. A Cepal de PREBISCH foi inovadora e sua contribuição decisiva para a reordenação do modelo de desenvolvimento preexistente em algumas nações latino-americanas. A participação dos governos em processos de industrialização em países como Brasil e Chile foi acelerada sob influência das idéias cepalinas, alterando, em diferentes medidas, os quadros social e econômico dessas nações. ${ }^{1}$ É por isso que tratar do pensamento cepalino, nos vários momentos de sua existência, tem sido tarefa necessária a todos que desejam compreender o desenvolvimento socioeconômico da América Latina em sua especificidade.

A proposta deste artigo é apresentar uma leitura das formulações cepalinas acerca da questão agrária, foco dos desequilíbrios gerados no setor agrícola latino-americano. Tomando-se como pano de fundo analítico o

* Economista pela Pontifícia Universidade Católica de São Paulo (PUC/SP) e Mestrando em História Econômica pelo Instituto de Economia da Universidade Estadual de Campinas (Unicamp).

1 Segundo FURTADO (1985, p. 103), "foi no Brasil onde, ao lado do Chile, germinaram as idéias da Cepal nessa primeira fase.” Cf. FURTADO, C. A fantasia organizada. 5. ed. Rio de Janeiro: Paz e Terra, 1985. 
problemático processo de industrialização da periferia, procurar-se-á demonstrar como a Cepal de Raúl PREBISCH sistematizou e analisou as barreiras, geradas no setor agrícola, a esse processo. Assim, será examinada a primeira conceituação teórica realizada pela Cepal sobre a estrutura agrária na maioria das nações latino-americanas e suas consequiências negativas ao modelo de desenvolvimento periférico baseado na industrialização. Para tal tarefa utilizarse-ão os textos de PREBISCH $(1949 ; 1950 ; 1951)$ na Cepal. Ainda neste artigo, apresentar-se-á, brevemente, a renovação ocorrida no pensamento cepalino (entre o final da década de 50 e o início da década de 60), com destaque para as formulações relacionadas à questão agrária, presentes no último texto de PREBISCH (1963) nessa comissão.

\section{A CePal e a CONDiÇão PERIFÉRICA}

A Comissão Econômica Para a América Latina (Cepal) é referência obrigatória a todos aqueles que se dedicam ao estudo do subdesenvolvimento e suas conseqüências na América Latina. Criada pela Organização das Nações Unidas (ONU) em 1948, a Cepal surgiu com o fito de explicar o atraso socioeconômico dos países latino-americanos (periferia) em relação aos grandes centros desenvolvidos (Estados Unidos e alguns países europeus) e, com isso, tentar encontrar formas, via estudos e projetos, para superá-lo. Para CARDOSO (1995, p. 30), a Cepal "canalizou e difundiu um conjunto de teses a respeito das causas, condições e obstáculos ao desenvolvimento, tornando-se uma espécie de marca registrada do pensamento econômico latino-americano." Entre outros intelectuais e economistas que participaram da Cepal, destacam-se o argentino Raúl PREBISCH, principal comandante dessa comissão, e o brasileiro Celso Furtado.

Sob a direção de PREBISCH, surgiu a chamada "Teoria Clássica da Cepal" (SCHWARZER, 1993, p. 7), constituída pelas suas primeiras e decisivas teses: ${ }^{2}$ o sistema "centro-periferia"; a "deterioração dos termos de intercâmbio"; e a "industrialização periférica". Nessas teses, por meio de indicadores empíricos, a Cepal procurava demonstrar que a difusão internacional do progresso técnico e de seus benefícios teria ocorrido de maneira diferenciada entre os países do centro e da periferia, deixando-os crescentemente distanciados em

2 Tais teses foram elaboradas pela Cepal entre o final da década de 40 e os primeiros anos da década de 50 . 
termos de desenvolvimento econômico e social. O centro estava se apossando dos frutos do progresso técnico em medida superior à alcançada nas nações periféricas, falseando a teoria clássica baseada nas vantagens comparativas da "divisão internacional do trabalho" em vigor no período. ${ }^{3}$ Nessa divisão do trabalho, a periferia seria responsável pelo fornecimento de bens primários às nações desenvolvidas e industrializadas que, por sua vez, retribuíam através da provisão de bens industrializados. Constituía-se, com isso, um quadro vicioso de "desvantagens reiterativas" (OLIVEIRA, 1983, p. 8), sustentado pela crescente deterioração dos termos de troca entre os preços dos produtos primários e os dos bens industrializados. Mediante esse cenário, a Cepal pregava a adoção de políticas governamentais deliberadamente industrialistas, caminho único, para os cepalinos, à superação da condição periférica.

O papel de conjunto de nações primário-exportadoras na "divisão internacional do trabalho" foi outorgado à América Latina a partir da segunda metade do século XIX, permitindo e ocasionando a aplicação de técnicas produtivas modernas nos setores ligados à exportação, seja para a eficiente vazão dos produtos primários, seja para o bom funcionamento das atividades econômicas relacionadas a essa prática. MELLO (1990, p. 29) lembra que, "de acordo com o paradigma cepalino", as exportações da periferia significavam, nesse período, "o único componente autônomo de crescimento da renda," dando ao setor exportador a posição de "centro dinâmico da economia". Esse período histórico da periferia foi denominado, pela Cepal, de fase de crescimento "para fora". Em tal fase, consolidar-se-ia uma estrutura econômico-produtiva marcada pelo modernismo do setor primário-exportador e pelo caráter arcaico dos demais setores internos, bem como pela baixa diversificação da produção

3 Trata-se da Teoria das Vantagens Comparativas de David Ricardo, cuja primeira formulação data de 1817. CARDOSO (1995, p. 30-34) lembra que tal teoria sofreu sucessivos aperfeiçoamentos e críticas em autores como Bertil Ohlin, em 1933, e Paul Samuelson, em 1948. Os primeiros trabalhos de PREBISCH na Cepal, em especial a elaboração/constatação do sistema centro-periferia e da deterioração dos termos de troca, constituíram-se como forte crítica às teorias sobre o comércio internacional vigentes no período, baseadas nas Vantagens Comparativas. Cf. CARDOSO, F. H. Originalidade da cópia: a Cepal e a idéia de desenvolvimento. In: As idéias e seu lugar. 2. ed. Petrópolis: Vozes, 1995. p. 27-80.

4 A atividade produtiva na periferia pôde ser caracterizada, segundo seu grau de diversificação e distribuição geral do avanço tecnológico, como especializada e heterogênea, indicando, para os cepalinos, o baixo nível de desenvolvimento socioeconômico predominante nessas nações. Os países industrializados (centro), sob esta mesma terminologia cepalina, seriam classificados como diversificados e homogêneos. 
(essencialmente matérias-primas). ${ }^{4}$

Importa notar que essas características históricas de atraso da estrutura produtiva permaneceram e se reproduziram durante a fase de industrialização periférica, na primeira metade do século XX. Nesse contexto, a indústria que emergiu de modo espontâneo, ${ }^{5}$ logo passou a ter feição problemática na América Latina. Trata-se de um novo período do desenvolvimento periférico, o de crescimento "para dentro", cuja dinâmica foi dada através da "substituição de importações". 6

E quais os desdobramentos gerados pela permanência e manutenção desse atraso durante a fase latino-americana de crescimento baseado na industrialização? A continuidade da dependência externa; o desemprego, via inadequada aplicação da tecnologia e excessiva oferta de mão-de-obra; a persistência das disparidades intersetoriais (próprias da heterogeneidade do sistema produtivo), mantidas pelo insuficiente padrão de acumulação dos setores atrasados e pela má distribuição dos investimentos nos diversos setores que compõem a estrutura produtiva; e, finalmente, os desequilíbrios gerados no setor agrícola. Este foi, de maneira genérica, o quadro-problema que suscitou o caráter específico do processo de industrialização na periferia.

5 Segundo RODRIGUEZ (1981, p. 43-48), o processo de industrialização na América Latina emergiu espontaneamente em meio ao atraso produtivo e econômico, característico dessa região na primeira metade do século XX, devido a fatores de ordem conjuntural (duas guerras mundiais e grande depressão econômica internacional) e estrutural (consolidação dos Estados Unidos como novo centro cíclico da economia mundial). Além da limitação à importação de bens industrializados, natural de períodos de guerra e de crise econômica, a periferia ainda teve como fator impulsionador para sua industrialização a substituição da Grã-Bretanha pelos Estados Unidos como centro dinâmico da economia mundial (Cf. RODRIGUEZ, O. Teoria do subdesenvolvimento da CEPAL. 1. ed. Rio de Janeiro: Forense-Universitária, 1981.). Quanto a este último motivo, FURTADO (1985, p. 77) lembra que se para a periferia o quadro já era "desfavorável fez-se ainda mais adverso com a tendência a um persistente declínio do coeficiente de importações desse país (Estados Unidos), o qual baixaria de 6 por cento, em 1925, para 3,1 por cento, em 1949."

6 TAVARES, em artigo publicado pela primeira vez em 1964, analisou a industrialização por substituição de importações como um processo já avançado e problemático. Segundo a autora, "o 'processo de substituição de importações' pode ser entendido como um processo de desenvolvimento 'parcial' e 'fechado' que, respondendo às restrições do comércio exterior, procurou repetir aceleradamente, em condições históricas distintas, a experiência de industrialização dos países desenvolvidos" (TAVARES, M. C. Da substituição de importações ao capitalismo financeiro: ensaios sobre economia brasileira. 1. ed. Rio de Janeiro: Zahar, 1972.). Tal processo "não visa diminuir o quantum de importação global; essa diminuição, quando ocorre, é imposta pelas restrições do setor externo e não desejada. Dessas restrições (absolutas ou relativas) decorre a necessidade de produzir internamente alguns bens que antes se importavam. Por outro lado, no lugar desses bens substituídos aparecem outros e à medida que o processo avança isso acarreta um aumento da demanda derivada por importações (de produtos intermediários e bens de capital) que pode resultar numa maior dependência do exterior, em comparação com as primeiras fases do processo de substituição." (TAVARES, 1972, p. 39) 


\section{INDUSTRIALIZAÇÃO, PROBLEMÁTICA AGRÍCOLA E QUESTÃo AGRÁRIA}

Durante a fase inicial da industrialização periférica, o setor agrícola se caracterizou pela insuficiente produção agropecuária (dirigida ao consumo interno) e pela incapacidade de manter um nível de emprego adequado ao ritmo de crescimento dos demais setores do sistema produtivo. No documento Problemas teóricos y prácticos del crecimiento económico, produzido por PREBISCH (1951), na Cepal, formulou-se, pela primeira vez nessa comissão, um breve conjunto de idéias a respeito dos obstáculos ao desenvolvimento econômico de base industrial, gerados através desses desequilíbrios do setor agrícola. O diferencial contido nessa análise estava no fato de que a Cepal aproximou, do ponto de vista teórico, estrutura agrária (tipo de propriedade e regime de posse da terra) e desequilíbrios gerados no setor agrícola. Surgiam, então, as primeiras formulações cepalinas quanto à questão agrária latino-americana, em meio ao contexto mais amplo de suas reflexões acerca da problemática industrialização periférica, foco de seu interesse analítico no período.

Serão retornadas agora as principais idéias dessa comissão relacionadas à questão agrária e à aplicação de políticas para sua resolução.

Para romper com a estrutura especializada e heterogênea que caracterizava a condição periférica, a Cepal recomendava, durante a fase de industrialização, que os investimentos oriundos da acumulação fossem estrategicamente distribuídos entre os setores atrasados e os setores modernos, permitindo a formação, a longo prazo, de uma estrutura produtiva moderna, diversificada e homogênea. Depreende-se daí que os desequilíbrios intersetoriais da periferia estavam vinculados ao baixo padrão tecnológico (e, por isso, à baixa produtividade do trabalho e do capital) observado em vários setores produtivos, os considerados atrasados. Deduz-se também que a inserção constante e crescente do progresso técnico na estrutura produtiva (em seus diversos setores) era vista como indispensável na busca da modernização da produção e do aumento global da renda. No caso da produção agrícola, ver-se-á que essa recomendação cepalina era parcialmente validada, em razão da especificidade dos modos de produção do setor referido e de suas conseqüências para o desenvolvimento do sistema produtivo como um todo.

Segundo RODRIGUEZ (1981, p. 89-90), para analisar a produção agrícola, a Cepal partiu do pressuposto genérico de que haviam dois tipos de técnicas de cultivo e combinação de recursos nesse setor. Eram eles: a mecanização do trabalho agrícola, caracterizada pela pequena utilização da mão-deobra por unidade de produto e de superfície de terra (aumento da produtividade 
do trabalho), sem grandes alterações na produtividade do solo; e os modos de cultivo dedicados à elevação da produtividade da terra por hectare, caracterizados pelo uso de fertilizantes e sementes selecionadas que aumentavam o rendimento da terra sem diminuir a quantidade de mão-de-obra empregada. De imediato, nota-se que no setor agrícola as técnicas de cultivo, caracterizadas pela baixa densidade de capital empregado por unidade produzida, podiam apresentar boa produtividade e eficiência.

PREBISCH (1951, p. 292-293) afirmou: "La mecanización también responde a una necesidad general ya que constituye, dentro del desarrollo económico, el medio por el cual se va creando el sobrante de población que la industria y otras actividades tendrán que absorber productivamente." Para a Cepal, mecanização significava modernização no setor agrícola. Significava também um estímulo ao desenvolvimento da estrutura produtiva (sobretudo setores industriais emergentes), através da liberação da mão-de-obra. No entanto, o que se observou é que, durante a fase inicial da industrialização, não havia capital disponível para a realização de investimentos que permitissem a absorção, nos setores urbanos, do contingente de mão-de-obra oriundo do campo. Geravase, por conseguinte, desemprego rural e urbano através da mecanização das terras. Ante esse quadro, PREBISCH (1951, p. 293) escreveu:

Pero, dada la abundancia de potencial humano en la tierra y la escasez de capitales, la mecanización debería ser en todo caso objeto de muy cuidadosa atención en los programas de desarrollo económico; tanto más cuanto que el capital escaso puede tener aplicación mucho más provechosa en el aumento del producto, sobre todo cuando se ha llegado al límite más allá del cual no podría absorberse el sobrante de mano de obra.

Não obstante a convicção cepalina de que a mecanização do setor agrícola seria um passo para a consolidação do desenvolvimento econômico baseado no progresso técnico, sua aplicação era passível de ponderação, uma vez que a liberação de mão-de-obra deveria ocorrer em dimensões necessárias e assimiláveis pelo sistema produtivo. Em um momento singular, a Cepal admitiu então que a opção de maior utilização do progresso técnico e de alta produtividade do capital e trabalho podia não ser, em alguns casos, a melhor escolha para o setor agrícola, da ótica do desenvolvimento econômico global. Para PREBISCH (1951, p. 292), na atividade agrícola "es posible diferenciar en la práctica las inversiones según el fin perseguido.” Assim, a maior utilização da mão-de-obra através de técnicas de cultivo de baixa densidade de capital empregado e elevação da produtividade da terra por hectare era vista como uma boa opção, mesmo que temporária, para aumentar a oferta interna agrícola e controlar o fluxo indesejado de trabalhadores do campo para os centros urbanos. 
Constatada a existência de opções de técnicas que alocam os recursos disponíveis de modo eficiente, o baixo padrão tecnológico não podia ser considerado a base dos desequilíbrios gerados no setor agrícola, a despeito do que ocorria com os demais setores produtivos. Nesse momento, a Cepal direcionou seus esforços na tentativa de compreender "el gran obstáculo del régimen de la tenencia de la tierra en muchos países" (PREBISCH, 1951, p. 295), buscando esclarecer a problemática inicialmente levantada.

Num primeiro passo, a Cepal identificou a existência de dois tipos básicos de propriedades agrárias na periferia: os latifúndios e os minifúndios. Em seguida, procurou entender o funcionamento dessas estruturas e sua influência na manutenção dos desequilíbrios originados no setor agrícola. Nesse processo, a Cepal encontrou, de modo intrínseco, as respostas à problemática estudada. Será estudado, agora, como se dava, na visão cepalina, a incompatibilidade entre estrutura agrária e aumento da oferta agropecuária com liberação de mão-de-obra em dimensões necessárias ao crescimento industrial periférico.

Nos latifúndios, propriedades rurais de grande extensão, havia, por razões econômicas, uma tendência à mecanização das terras, com influências negativas sobre o uso da força de trabalho. Terras concentradas em posse de poucos proprietários eram de difícil aproveitamento, em virtude da alta necessidade de capital disponível para utilizá-las adequadamente. Quando eram devidamente, ou ao menos parcialmente, aproveitadas para a obtenção de certos níveis de produtividade e rendimentos, eram mediante a mecanização e a baixa utilização de mão-de-obra. Para muitos latifundiários, mesmo com a abundância de mão-de-obra disponível, era menos custoso mecanizar as terras, num processo de substituição de mão-de-obra por capital. Dado o ritmo de crescimento econômico da fase de industrialização, tornou-se impossível absorver tal contingente de trabalhadores nas grandes cidades.

Por outro lado, no caso dos latifúndios, sabia-se que, em muitas nações da América Latina, a posse de grandes extensões de terras improdutivas poderia ser desejável por seus proprietários. A não utilização da terra, ou de parte dela, era até mesmo vantajosa para os latifundiários, sobretudo quando se considerava os gastos necessários para a produção agrícola. Por fim, deve-se considerar que, na América Latina, a posse de grandes extensões de terras, ainda que improdutivas, servia também para a manutenção da influência e do prestígio político-social de que usufruíam seus proprietários.

Nas pequenas propriedades rurais, os minifúndios, pela débil capacidade de acumular, eram aplicadas técnicas rudimentares de cultivo da terra combinadas com baixos níveis de produtividade da mão-de-obra empregada. Tornava-se difícil o aumento da produção, impedindo a expansão da oferta agríco- 
la. A capacidade de retenção da mão-de-obra ficava também comprometida já que a pequena quantidade de terra não era capaz, por si só, de dar condições mínimas de subsistência à população que nela habitava e trabalhava. Num processo circular e cumulativo, verificava-se que, nos minifúndios, a incapacidade de acumular e investir contribuía para o desemprego urbano, via transferências de trabalhadores do campo para as cidades, e para a insuficiência da oferta de produtos agrícolas, inadequada ao modelo de crescimento baseado na industrialização.

No caso do aluguel de pequenas propriedades rurais, havia a necessidade de investimentos, por parte dos seus locatários, de recursos incompatíveis ao próprio valor delas. Dessa maneira, o uso freqüente de máquinas e equipamentos para o cultivo, além de economicamente pouco viável, ocasionava, como nos latifúndios, a baixa utilização da mão-de-obra, com consequiências já vistas sobre a sua distribuição.

Em suma, os latifúndios e os minifúndios, através da má utilização da mão-de-obra e da inadequada aplicação de técnicas para o cultivo das terras, contribuíam para o aumento do desemprego urbano e rural e para a manutenção da insuficiente oferta agropecuária para o mercado interno na fase de industrialização periférica. Somava-se a isso o baixo poder de acumulação de capital nesse setor, responsável pela reduzida taxa de investimentos destinados ao aumento da produção. Estava dado, pela Cepal, o diagnóstico dos desequilíbrios gerados no setor agrícola durante o período em questão.

No ideário cepalino, a industrialização, sob a égide da condução estatal, consolidar-se-ia como o principal caminho à superação da condição periférica. Para atingir os níveis de produtividade desejados e otimizar a alocação de recursos na atividade industrial, a utilização de técnicas de programação pelos governos foi colocada, pela Cepal, como o modo mais racional e eficiente em meio às políticas que visavam a industrialização. Com isso, passar-se-ia de industrialização espontânea, e ao mesmo tempo problemática, à industrialização deliberada e programada, através do suporte governamental.

Tal qual a industrialização deliberada, o setor agrícola na periferia também deveria ser conduzido através de políticas governamentais. As recomendações da Cepal de PREBISCH, no que diz respeito à aplicação de uma política agrária, estavam concentradas em duas possíveis ações governamentais: no incentivo à utilização de um sistema adequado e eficiente de tributação à propriedade agrária, desestimulando a manutenção de estruturas pouco produtivas; ou na reforma da estrutura agrária, ação capaz de romper diretamente com as grandes estruturas improdutivas que conspiravam contra a industrialização. Conforme a especificidade do caso, a combinação dessas duas ações era vista como uma alternativa possível e eficaz. 
Além dessas medidas, os investimentos governamentais e o apoio do Estado ao uso de técnicas de experimentação e difusão de práticas que permitam o aumento da produção agrícola eram pregados pelos cepalinos. Vale ressaltar que, nesse primeiro momento de interpretação da industrialização latinoamericana, a Cepal pregava que a aplicação de tais políticas devia acontecer de acordo com as condições e as necessidades específicas de cada nação ou mesmo região. PREBISCH (1951, p. 296) foi claro: "En regiones en que no es la tenencia en sí, sino la falta de inversiones y de acción técnica del Estado lo que está retardando el progreso agrícola, la solución no puede ser la misma que en otras en que la forma de tenencia es el gran obstáculo que se interpone."

\section{Renovando velhas idéias: a Cepal nos anos sessenta}

Entre os últimos anos da década de 50 e os primeiros anos da década de 60, ocorreu uma espécie de renovação, encabeçada por PREBISCH, no ideário cepalino. Não se trata de uma revisão das idéias da Cepal. O que ocorreu foi uma adaptação do enfoque metodológico ${ }^{7}$ próprio dessa comissão às exigências do momento histórico. Segundo BIELSCHOWSKY (1998, p. 11), "lo que se va modificando es la historia real objeto del análisis, así como el contexto ideológico en que ésta se genera, lo que obliga permanentemente a matizar los énfasis y a renovar interpretaciones, a fin de adaptarse a los nuevos contextos históricos."

Em um primeiro momento, início da década de 50, a Cepal acreditava que através do dinamismo econômico, gerado pelo processo de industrialização, seria possível atingir o nível desejado de produtividade do trabalho e que, nessa prática, aconteceria o rompimento ou, ao menos, a diminuição dos desequilíbrios ${ }^{8}$ próprios desse processo nas nações periféricas. Já na nova fase,

7 BIELSCHOWSKY (1998, p. 11-12) identifica que há quatro enfoques comuns que permeiam o método de análise utilizado pela Cepal em seus cinqüenta anos de existência: o "enfoque histórico-estructuralista" (baseado na relação centro-periferia); a "análisis de la inserción internacional"; a "análisis de los condicionantes estructurales internos" (do crescimento e do progresso técnico, e de suas relações com emprego e distribuição de renda); e a "análisis de las necesidades y posibilidades de acción estatal”. Cf. BIELSCHOWSKY, R. Cincuenta años de pensamiento en la CEPAL: una resenã. In: CEPAL. Cincuenta años de pensamiento en la CEPAL: textos selecionados. 1. ed. Santiago: Fondo de Cultura Económica / CEPAL, 1998. v. 1, p. 9-61.

8 Esses desequilíbrios gerados ou salientados durante o processo de industrialização na periferia foram brevemente citados no primeiro tópico deste artigo. 
tal crença seria abalada pela notoriedade dos obstáculos ao desenvolvimento surgidos a partir desses desequilíbrios da etapa inicial da industrialização periférica. É nesse momento de reflexão que PREBISCH passou, sob influência do sociólogo cepalino José Medina Echavarría, a incorporar contribuições de cunho sociológico às formulações da Cepal, uma vez que o dinamismo do processo de industrialização não havia sido suficiente para promover a elevação das condições de vida das massas, o que permitiria, ao mesmo tempo, a continuidade do próprio processo, através de condições sociopolíticas favoráveis, numa cadeia de causação circular. Os possíveis efeitos positivos do crescimento industrial na periferia estavam sendo distorcidos, do ponto de vista da distribuição de seus benefícios na sociedade. No caso do Brasil, para citar um exemplo, mesmo com o dinamismo atingido pelo processo de industrialização durante a década de 50, observavam-se, no início da década de 60, a recessão, a manutenção do baixo padrão de vida da maior parte da população, a inflação e a concentração de renda se tornarem fatores crônicos e marcantes na realidade socioeconômica do país.

Convém então enumerar, de modo sintético, quais os fatos que teriam servido de obstáculo ao desenvolvimento econômico baseado na dinâmica do referido processo, ocasionando esta renovação nas reflexões cepalinas.

O primeiro fato era a tendência à estagnação na América Latina, percebida através da diminuição do crescimento do produto por habitante que, segundo RODRIGUEZ (1981, p. 181-182), chegou a taxas negativas entre 1961 e 1963. Em seguida, deve-se destacar o aumento constante do desemprego e do subemprego da população ativa: nas áreas urbanas, caracterizado pelo aumento do desemprego aberto, e, no meio rural, pelo desemprego temporário ou proliferação dos subempregos (subutilização da mão-de-obra). Também mereciam relevo o crônico déficit do balanço de pagamentos, gerado através do próprio processo de industrialização por "substituição de importações", e os altos índices de inflação que, em última instância, implicavam em aumento das tensões sociais via quedas constantes nos padrões de consumo da população. Nesse contexto, o processo de aceleração da concentração da renda nas camadas sociais de maior poderio econômico tornou-se, praticamente, inevitável, com conseqüências nefastas para o bem-estar coletivo.

Em resposta a esse cenário, a Cepal passou a pregar que os governos deveriam agir a fim de redistribuir a renda e de promover a reorientação do modelo de desenvolvimento econômico. Agora, desenvolvimento econômico e elevação do nível de vida das massas deveriam acontecer simultaneamente, ainda sob orientação do governo. Já o processo de concentração de renda deveria ser evitado, bloqueado. Na realidade, os ideais cepalinos como a industrializa- 
ção planejada e a necessidade de governos fortes e intervencionistas não se perderam nem se enfraqueceram nessa nova fase: foram apenas complementados pela preocupação com a crescente problemática social. PREBISCH (1963, p. 144), no principal texto desta nova fase, afirmou:

[...] la América Latina tiene que acelerar su ritmo de desarrollo económico y redistribuir el ingreso en favor de las masas populares. El cumplimiento de este objetivo no podrá dilatarse indefinidamente; ni cabría esperar que el desarrollo económico se presentara primero y luego sobreviniera, como natural consecuencia, el desarrollo social. Ambos tienen que irse cumpliendo de modo acompasado.

\section{A QUESTÃo AGRÁRIA}

No renovado pensamento cepalino, diminui-se a importância dada às anteriores questões relacionadas à oferta agrícola e à distribuição da mão-deobra e abriu-se caminho para a preocupação com a incidência da estrutura agrária na alocação dos recursos e da renda no sistema econômico como um todo. BIELSCHOWSKY (1998, p. 32), ao referir-se ao pensamento cepalino na década de 60, afirmou: "el modelo explicativo sobre la falta de capacidad para absorber la fuerza de trabajo que figuraba en los textos de los años cincuenta insuficiencia del ahorro y utilización de tecnologías intensivas en capital - se orienta ahora al análisis del uso social del excedente potencial". Aconteceu, desta forma, a passagem para uma reflexão mais global que contemplaria o papel da estrutura agrária na inadequada distribuição da renda (e do emprego) existente no setor agrícola e, logo, em todo o sistema. Nesse caminho, a reforma agrária assumiu, junto à ação técnica e impulsionadora do Estado para com a produção agrícola, um papel relevante para a consolidação do desejado aumento dos níveis de vida das massas e, logo, para o alívio das tensões sociais.

As primeiras demonstrações dessa nova fase apareceram em um trabalho ${ }^{9}$ produzido em 1961 pela Cepal, em conjunto com a FAO.$^{10}$ Mas foi somente em 1963 que PREBISCH e a Cepal, através de seu principal estudo nesse período, adotaram uma postura própria, uma vez que estava disposta em total concordância com os demais cânones dessa comissão. Ver-se-á, através desse

9 Trata-se do artigo da Cepal/FAO. Una política agrícola para acelerar el desarrollo económico de América Latina. Boletín Económico de América Latina/Cepal, v. 6, n. 2, p. 1-12, 1961.

10 A FAO é uma organização, também pertencente às Nações Unidas, que realiza estudos destinados a apontar soluções para os problemas ligados à agricultura e à alimentação nos diversos países. 
basilar estudo, como foi contemplada a questão agrária nessa nova fase.

PREBISCH (1963, p. 167-168) iniciou seu estudo expondo que, nas décadas de 40 e 50 o crescimento da produção agrícola latino-americana fora cerca de $0,2 \%$ maior que o crescimento de sua população, permitindo uma demanda interna de produtos agrícolas muito superior ao volume ofertado internamente por essa produção. Havia então, pelo diagnóstico cepalino, necessidade de que se aumentasse a produção agrícola, ocasionando o desejado aumento da renda nesse setor e permitindo o equilíbrio entre demanda e oferta de bens agrícolas no mercado interno. Mas como atingir esse aumento de produtividade? A Cepal pregou o melhor aproveitamento das terras já ocupadas e o uso de técnicas de cultivo que proporcionassem o aumento da produtividade da terra via o melhor aproveitamento da mão-de-obra disponível. A possibilidade de expansão das fronteiras agrícolas através da utilização de novas terras que aumentariam a área para agricultura era considerada pouco viável e desnecessária, já que as terras ocupadas eram mal aproveitadas e apresentavam baixa produtividade. Era na transformação da histórica estrutura agrária que estava, para a Cepal, a solução da problemática agrícola e da má distribuição da renda oriunda desse setor.

Considerando-se que o aumento de renda gerado na elevação da produtividade também cumpria importantes finalidades sociais, posto que ocasionaria o aumento da renda por habitante no precário setor rural, a reforma agrária apareceu como a única ação, pela Cepal, capaz de realizar o necessário reaproveitamento das terras pouco produtivas. Era nesse momento que, segundo PREBISCH (1963, p. 169-170):

La reforma se necesita impostergablemente por tres razones primordiales: a) realizar un cambio estructural que permita aprovechar intensamente el potencial de ahorro y promueva la movilidad social, con importantes consecuencias económicas, sociales y políticas; b) satisfacer la demanda de una población que crece rápidamente y tiene de mejorar su dieta, y c) elevar el nivel de vida de las masas rurales.

A reforma agrária se tornou a principal ação governamental com o fito de transformar a estrutura agrária e, por conseguinte, permitir a desejada elevação dos níveis de vida das massas camponesas: neste caminho, o aumento da renda permitiria benefícios diretos para a população rural, com efeitos imediatos para o alívio das tensões sociais. Por isso que, em um período de tendência à estagnação na América Latina, a reforma deveria ocorrer de maneira "rápida y masiva" (PREBISCH, 1963, p. 170).

Por fim, é importante destacar que a Cepal e PREBISCH (1963, p. 171) procuraram deixar claro que "resuelto el problema de tenencia, el comple- 
mento ineludible de la acción técnica del Estado es el incentivo a los productores". Era imprescindível que a reforma agrária, para que pudesse atingir seus objetivos primordiais, fosse acompanhada de uma ação protetora e incentivadora do Estado. Tal incentivo seria realizado através da assistência técnica e creditícia do Estado ao produtor agrícola e da prática governamental de uma política de preços que permitisse o crescimento da renda nesse setor. Assim, seria possível transpor ou, ao menos, reduzir os obstáculos ao aumento da renda na produção agrícola. Vale ainda lembrar, como estorvo a esse aumento, a "deterioração interna dos termos de intercâmbio" entre os preços dos produtos agrícolas e os dos bens industrializados produzidos em uma mesma nação, que encontrava força na proteção governamental à produção urbana que, nesse caso, agia contrariamente ao desenvolvimento do setor agrícola. ${ }^{11}$

\section{CONSIDERAÇÕES FINAIS}

Em um primeiro momento de interpretação, a Cepal, ao examinar os desequilíbrios de origem agrícola, notou que somente através do entendimento da estrutura agrária latino-americana se encontraria a resposta à problemática gerada nesse setor. A solução consistia na aplicação de políticas governamentais destinadas à realização da reforma da estrutura agrária (respeitando as particularidades de cada nação ou região) e/ou da aplicação de tributos para as terras improdutivas, permitindo, com isso, a harmonização entre produção agropecuária, fluxo de mão-de-obra do campo para as cidades e modelo periférico de desenvolvimento baseado na industrialização. O setor agrícola na periferia deveria ser conduzido através de políticas governamentais deliberadas, a exemplo do desejado processo de industrialização planejada.

Já a renovação ocorrida no ideário cepalino a partir do final da década de 50 se caracterizou mais pelo aumento da preocupação com as questões de

11 O documento "Uma política de desenvolvimento econômico para o Nordeste" produzido pelo Grupo de Trabalho para o Desenvolvimento do Nordeste (GTDN, 1959), sob o comando de Celso Furtado, procurou demonstrar, aos moldes cepalinos, que havia, entre o Nordeste e o Centro-Sul do Brasil, uma relação típica entre centros produtores de bens industrializados e periferias produtoras de matérias-primas. Tal relação estaria baseada em uma deterioração dos termos de troca entre as regiões, indicando, ao longo do tempo, que o poder de compra da região arcaica e agrícola (Nordeste) seria cada vez menor em relação ao da moderna e industrializada (Centro-Sul). Cf. GTDN. Uma política de desenvolvimento econômico para o Nordeste. In: VERSIANI, F. R.; BARROS, J. R. M. (Org.). Formação econômica do Brasil: a experiência da industrialização. 1. ed. São Paulo: Saraiva, 1977. p. 293-338. 
cunho social do que pela inovação teórica/conceitual. Mediante o fortalecimento das barreiras ao processo de industrialização e o aumento das tensões político-sociais geradas pela tendência à estagnação econômica latino-americana, a Cepal passou a pregar a aplicação, por parte dos governos dessa região, de um modelo de desenvolvimento direcionado à distribuição eqüitativa e global da renda. Os pilares do ideário cepalino permaneceram intocados, como a industrialização planejada e a necessidade de participação do governo na condução do processo de desenvolvimento econômico. Nesse momento, a reforma agrária e o apoio (técnico e creditício) aos pequenos produtores rurais, como políticas governamentais, ganharam força na defesa do processo de aumento dos níveis de vida das massas camponesas e na busca de um modelo de crescimento econômico acompanhado de justiça social.

Mas o que representa hoje recuperar algumas das idéias da Cepal de PREBISCH? Difícil responder, talvez. Tome-se apenas duas das idéias, presentes neste trabalho, defendidas pela Cepal: a necessidade de participação do Estado no processo de rompimento com o subdesenvolvimento em nações ou regiões atrasadas e a importância da reforma agrária como meio de controle do fluxo de mão-de-obra entre os setores industrial e agrícola.

Ao se considerar o presente quadro da economia brasileira, e especificamente o das disparidades regionais, pode-se supor o quão necessária é a presença do Estado na promoção do desenvolvimento de regiões com enorme dívida social, como a do Nordeste. Em contrapartida, tem-se observado que a inserção da economia brasileira no contexto da globalização dos mercados e a tendência geral ao uso da lógica das empresas transnacionais na condução da atividade econômica (pelos governos nacionais) têm justificado, na esfera político-econômica, a ausência do Estado brasileiro na tarefa do desenvolvimento. Como conseqüência, faz-se presente uma tendência à "tensões inter-regionais, à exacerbação de rivalidades corporativas e à formação de bolsões de miséria, tudo apontando para a inviabilização do país como projeto nacional" (FURTADO, 1992, p. 35). Problemáticas históricas como a do Nordeste, nesse cenário, são potencializadas, através do esvaziamento das políticas regionais de desenvolvimento.

Outro ponto que, por fim, merece rápida reflexão, está relacionado à reforma agrária. Com freqüência, há o contato com pesquisas que apresentam índices nada animadores de nível de emprego no Brasil. O fim do Estado desenvolvimentista, o impacto da abertura econômica, a flexibilização do mercado de trabalho e a emergência de um novo paradigma tecnológico e organizacional são alguns dos fatores que justificam e dão força a esse fenômeno. Logo, a resolução da questão agrária, como meta de políticas governamentais, não representaria um certo alívio para a problemática do desemprego? É revelante terminar com o alerta de FURTADO (1997, p. 71): 
[...]no Brasil tem essa situação particular que reúne abundância de terras férteis não utilizadas, acessíveis, já com infra-estrutura. E uma mão-deobra, caso único, querendo voltar para a agricultura. Isso sim que é um milagre! Em que parte do mundo, em que país do mundo tem gente querendo voltar para o trabalho agrícola? Somente no Brasil, onde a opção é ficar debaixo das pontes na cidade.

\title{
RESUMO
}

A proposta deste artigo é apresentar as formulações da Cepal de Raúl Prebisch relacionadas à questão agrária, foco dos desequilíbrios gerados no setor agrícola durante a industrialização latino-americana. Para tal, considerar-se-ão os textos da Cepal em dois momentos: início da década de 50, período marcado pelo otimismo cepalino em relação aos possíveis resultados de políticas governamentais de industrialização; e início da década de 60 , período em que Prebisch passa a incorporar questões de cunho social às formulações da Cepal, uma vez que o dinamismo do processo de industrialização não havia sido suficiente para promover melhores condições de vida para as massas de trabalhadores.

\begin{abstract}
The purpose of this article is to introduce Raúl Prebisch ECLAC's formulations related with the agrarian question, centre of instabilities generated in the agricultural sector during the Latin American industrialization process. To develop this article, ECLAC's papers will be evaluated in two different moments. Beginning of 50's: marked by ECLAC's optimism regarding the possible results of industrialization governmental policies. Beginning of 60's: Prebisch starts to include social questions on ECLAC's formulations, once the dynamism of industrialization process was not capable to promote better living conditions to the labouring classes.
\end{abstract}

\section{REFERÊNCIAS}

BIELSCHOWSKY, R. Pensamento econômico brasileiro: o ciclo ideológico do desenvolvimentismo. 3. ed. Rio de Janeiro: Contraponto, 1996.

Cincuenta años del pensamiento de la CEPAL: una reseña. In: CEPAL. Cincuenta años de pensamiento en la CEPAL: textos seleccionados. 1. ed. Santiago: Fondo de Cultura Económica/ CEPAL, 1998. v. 1, cap. 1, p. 9-61. 
PELLEGRINO, A. C. G. T. As Idéias da CEPAL sobre a questão agrária...

CARDOSO, F. H. Originalidade da cópia: a CEPAL e a idéia de desenvolvimento. In: As idéias e seu lugar. 2. ed. Petrópolis: Vozes, 1995. p. 27-80.

FURTADO, C. Formação econômica da América Latina. 1. ed. Rio de Janeiro: Lia S.A., 1970. . A fantasia organizada. 5. ed. Rio de Janeiro: Paz e Terra, 1985. Brasil: a construção interrompida. 1. ed. Rio de Janeiro: Paz e Terra, 1992. Celso Furtado: decifrando o Brasil (entrevista). Revista Democracia Viva, ano 1, n. 1, p. 58-77, 1997.

GOLDENSTEIN, L. Repensando a dependência. 1. ed. São Paulo: Paz e Terra, 1994.

GTDN. Uma política de desenvolvimento econômico para o Nordeste (1959). In: VERSIANI, F. R., BARROS, J. R. M. (Org.). Formação econômica do Brasil: a experiência da industrialização. 1. ed. São Paulo: Saraiva, 1977. p. 293-338.

GURRIERI, A. La economía política de Raúl Prebisch. In: CEPAL. México DF: Fondo de Cultura Económica, 1982. v. 1, p. 13-95.

MELLO, J. M. C. de. O capitalismo tardio. 8. ed. São Paulo: Brasiliense, 1990.

CEPAL/FAO. Una política agrícola para acelerar el desarrollo económico de América Latina. Boletín Económico de América Latina/CEPAL, v. 6, n. 2, p. 1-12, 1961.

OLIVEIRA, F. Celso Furtado. 1. ed. São Paulo: Ática, 1983.

PREBISCH, R. O desenvolvimento econômico da América Latina e seus principais problemas. Revista Brasileira de Economia, v. 3, n. 3, p. 47-112, 1949.

Crecimiento, desequilibrio y disparidades: interpretación del proceso de desarrollo económico. (1950). In: GURRIERI, A. La obra de Prebisch en la CEPAL. México DF: Fondo de Cultura Económica, 1982. v. 1, p. 56-247.

Problemas teóricos y prácticos del crecimiento económico. (1951). In: GURRIERI, A. La obra de Prebisch en la CEPAL. México DF: Fondo de Cultura Económica, 1982. v. 1, p. 248-297.

Hacia una dinámica del desarrollo latinoamericano. (1963). In: GURRIERI, A. La obra de Prebisch en la CEPAL. México DF: Fondo de Cultura Económica, 1982. v. 2, p. 137-227.

Cinco etapas de mi pensamiento sobre el desarrollo. El Trimestre Económico, v. 198, p. 1077-1096, 1983.

RODRIGUEZ, O. Teoria do subdesenvolvimento da CEPAL. 1. ed. Rio de Janeiro: Forense-Universitária, 1981.

et al. CEPAL: velhas e novas idéias. Revista Economia e Sociedade/IE-Unicamp, v. 5, p. 79-109, 1995.

SCHWARZER, H. A CEPAL: a teoria clássica e a proposta de transformação produtiva com eqüidade social. Curitiba, 1993. Dissertação (Mestrado) - Universidade Federal do Paraná.

TAVARES, M. C. Da substituição de importações ao capitalismo financeiro: ensaios sobre economia brasileira. 1. ed. Rio de Janeiro: Zahar, 1972. 